\title{
SCIDiC
}

International Journal of Dentistry and Oral Science (IJDOS)

ISSN: 2377-8075

\section{Dentist's Preference Of Mode Of Teaching Brushing Techniques To Children With Permanent Dentition}

Research Article

Vidyashri.S ${ }^{1}$, Vignesh Ravindran ${ }^{2 *}$

${ }^{1}$ BDS Third Year Student, Saveetha Dental College and Hospitals, Saveetha Institute of Medical and Technical Sciences, Saveetha University, Chennai, India.

${ }^{2}$ Senior Lecturer, Department of Pediatric and Preventive Dentistry, Saveetha Dental College and Hospitals, Saveetha Institute of Medical and Technical Sciences [SIMATS], Saveetha University, Chennai- 77, India.

Abstract

Introduction: Proper effective brushing of teeth aids in the management of dental caries and periodontal disease, which can lead to eating difficulties, pain, esthetician problems, malnutrition, reducing self estimation, and consequently reducing the quality of life. The method of teaching plays an important role in maintaining oral hygiene in children. The instructions should be given according to the child's degree of readiness for learning brushing techniques and should include reinforcement and systemic training.

Aim: to assess the common methods of teaching tooth brushing in young children with permanent dentition.

Materials and Methods: From the patients visiting the private dental hospital, those of the age group 13 to 18 years were considered in the inclusion criteria. Exclusion criteria involved those with poor maintenance of records and follow-up of uncooperative patients. The final sample size was 100 . The gender and age were considered and tabulated, followed by their statistical analysis using SPSS software version.

Results: From the results of the current study, the most preferred method of teaching brushing technique to children was found to be audiovisual aids such as electronic devices $(89 \%)$, while $8 \%$ preferred to demonstrate using cast and $2 \%$ preferred vocal training and reinforcement. Electronic devices were commonly used to demonstrate for both male and female patients which was statistically significant. $(\mathrm{p}$ value $=0.02)$

Conclusion: Within the limits of this study, it can be concluded that using audiovisual aids like electronic devices were majorly preferred among dentists to teach children of 13 to 18 years of age (permanent dentition) about the proper methods of brushing. This data is useful because this method is both inexpensive and easily taught.

Keywords: Brushing Techniques; Innovative Methods; Permanent Dentition; Dental Caries.

\section{Introduction}

Dental caries, or tooth decay, is an infectious process that leads to damage of the tooth by causing breakdown of the tooth enamel. Caries is caused by the complex interaction between acidproducing cariogenic bacteria in combination with fermentable carbohydrates intake in diet and other dietary, genetic, behavioral, social, and cultural factors [1]. Children are susceptible to caries as soon as the first teeth appear, which usually occurs around age 6 months [2]. Poor oral hygiene in children may lead to the early loss of permanent teeth due to caries and periodontal problems. Poor dental hygiene among the school children can have many detrimental effects on children, some more major than others. One of these effects is physical pain due to deeper spread of caries which leads to eating problems, sleeping problems and behavioral problems [3], all of which at such a young age should be avoided as much as possible. According to American Dental Association, oral health is the aesthetic, functional, structural, physiologic and psychosocial state of well-being and is important to an individual's general health and quality of life. Maintaining good oral hygiene is considered a lifelong habit [4]. Mover, these oral habits are to be undertaken at an early stage of life. It is imperative to teach

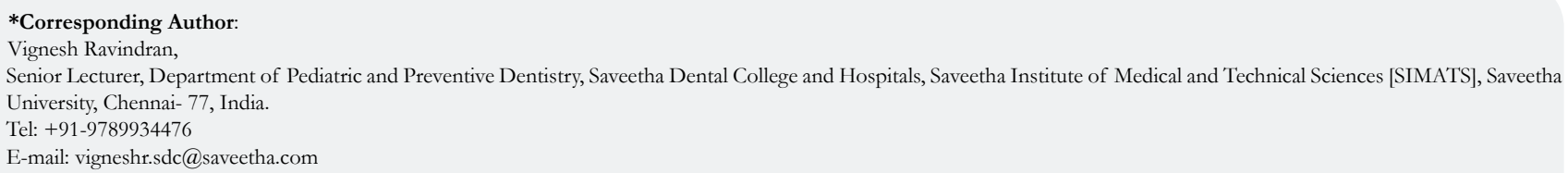

Citation: Vidyashri.S, Vignesh Ravindran. Dentist's Preference Of Mode Of Teaching Brushing Techniques To Children With Permanent Dentition. Int J Dentistry Oral Sci. 2021;8(9):4495-4499. doi: http://dx.doi.org/10.19070/2377-8075-21000914

Copyright: Vignesh Ravindran ${ }^{\circ} 2021$. This is an open-access article distributed under the terms of the Creative Commons Attribution License, which permits unrestricted use, distribution and reproduction in any medium, provided the original author and source are credited. 
its importance to children in order to increase their knowledge on maintaining good oral hygiene and a positive attitude towards oral health. A better knowledge about oral health is needed for good oral health related behaviour [5].

Proper effective brushing of teeth aids in the management of dental caries and periodontal disease, which can lead to eating difficulties, pain, esthetician problems, malnutrition, reducing self estimation, and consequently reducing the quality of life [1]. The principal etiological factor in dental caries and gingivitis is dental plaque. Removal of plaque from tooth surfaces using proper brushing technique can help in the management of both periodontal problems and caries. The various methods of tooth brushing used are Fones brushing technique, Bass brushing technique, Modified Bass brushing technique, Scrub brushing technique, Charters brushing technique, Roll brushing technique and Stillman brushing technique [6]. These techniques are effective in removing plaque biofilm and debris from the surface of the teeth, stimulates the gingiva and aids in delivery of fluoridated dentifrice to the tooth surfaces [7]. According to previous studies, Fones technique is the most commonly preferred brushing technique to be taught to children [8]. It was also observed that the average percentage of plaque removal from the lingual and labial tooth surface was higher in Fones method compared to other techniques $[8,9]$.

The method of teaching plays an important role in maintaining oral hygiene in children. The instructions should be given according to the child's degree of readiness for learning brushing techniques and should include reinforcement and systemic training [10]. Although manual dexterity and ability are needed to properly implement such techniques, intensive individual training is crucial. The physiological development of children plays a major role in the method of education in oral self-care. Oral hygiene instructions through individual educational lectures result in highly significant improvements in oral health. However, the grammatical understanding in young children could impede such techniques [11]. This can lead to the difficulty in training and practice of oral hygiene techniques in children using instructions taught verbally [12]. The use of audiovisual methods is also suggested for such children [13]. Our team has extensive knowledge and research experience that has translate into high quality publications [14-26, 27-33]. This study was undertaken with the aim to assess the common methods of teaching tooth brushing in young children with permanent dentition.

\section{Materials and Methods}

This retrospective study was conducted as a university setting which includes children of age group 13 to 18 . The approval for this study was obtained from the institutional ethical committee (ethical approval number: SDC/SIHEC/2020/DIASDATA/0619-0320). This study had advantages of large data availability, similar ethnicity, but it had disadvantages of smaller sample size, geographic limitation and no external validity. This was a convenience sampling conducted between June 2019 to March 2020. Data was collected from the dental records, patient management records of the Department of Pediatric Dentistry. The number of case sheets reviewed was 1000 . Inclusion criteria were the patients with permanent dentition (13 to 18 years). Patients with only primary dentition ( $0-5$ years) and mixed dentition $(\geq 13$ years), including the incomplete and repeated data were excluded from the study. Cross verification was done using a photographic method to eliminate the errors made while recording. To eliminate bias, simple random sampling was done. Final sample size taken up for the study was 700 cases. The data obtained were tabulated in excel, imported to SPSS software by IBM, a statistical software with variables defined. The significance of this study was obtained using the statistical test, Chi-Square and the results were interpreted.

\section{Results}

$18.14 \%$ of the subjects were 13 years old, $12.86 \%$ were 14 years old, $14 \%$ were 15 years old, $20.14 \%$ were 16 years old, 34.43 were 17 years old and $0.43 \%$ were 18 years old (Figure 1 ). $51.51 \%$ of the subjects were male children and 48.43 of them were female children (Figure 2). 89\% of the Dental students preferred electronic devices as a method of teaching while $9 \%$ used demonstration using cast and $2 \%$ used vocal method of teaching (Figure 3). Electronic devices were commonly used to demonstrate for both male and female patients which was statistically significant (Figure 4). $(\mathrm{p}$ value $=0.02)$.

\section{Discussion}

Proper tooth brushing technique is required in order to ensure good oral hygiene. It aids in the prevention of plaque accumulation, gingiva, and periodontal diseases [34]. Plaque accumulation is the primary cause for inflammation of gingiva and can result in compromised periodontal health. The lingual surfaces of the teeth are often overlooked during the brushing process leading to increased plaque accumulation in that area which causes compromised oral health [35]. The relation between incomplete plaque

Figure 1. The bar graph represents the frequency distribution of age groups of patients. Lilac represents patients who are 13 years old, grey represents 14 year olds, pink represents 15 year olds, orange represents 16 year olds, red represents 17 year olds, and ye1low represents 18 year old patients. $18.14 \%$ of the subjects were 13 years old, $12.86 \%$ were 14 years old, $14 \%$ were 15 years old, $20.14 \%$ were 16 years old, 34.43 were 17 years old and $0.43 \%$ were 18 years old.

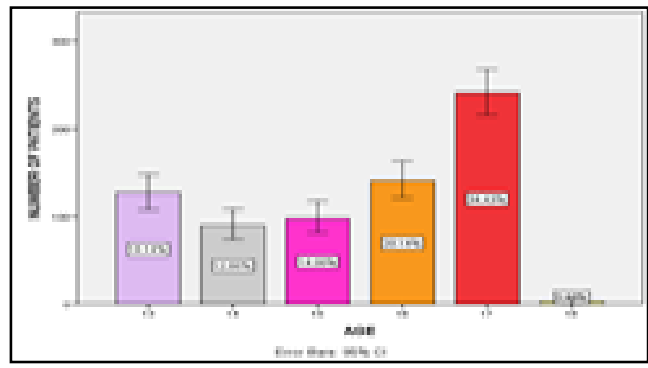


Figure 2. The bar graph represents the frequency distribution of gender of patients. Light blue represents male while brown represents female. $51.51 \%$ of the subjects were male and 48.43 of them were female.

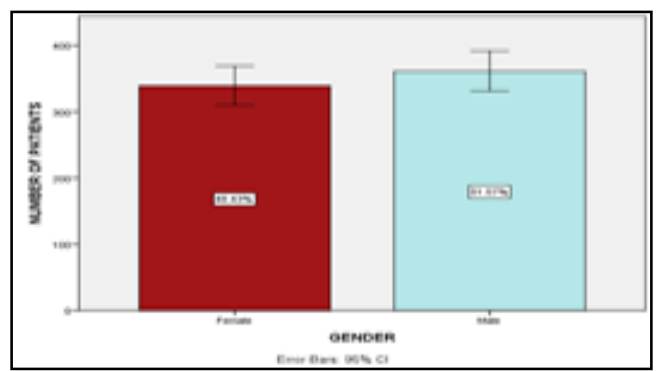

Figure 3. The bar graph represents the frequency distribution of modes of teaching methods preferred by dentists. The blue colour indicates teaching using electronic devices; green indicates demonstration using cast and yellow indicates vocal training. $\mathbf{8 9 \%}$ of the Dental students preferred electronic devices as a method of teaching while $\mathbf{9 \%}$ used demonstration using cast and $2 \%$ used vocal method of teaching.

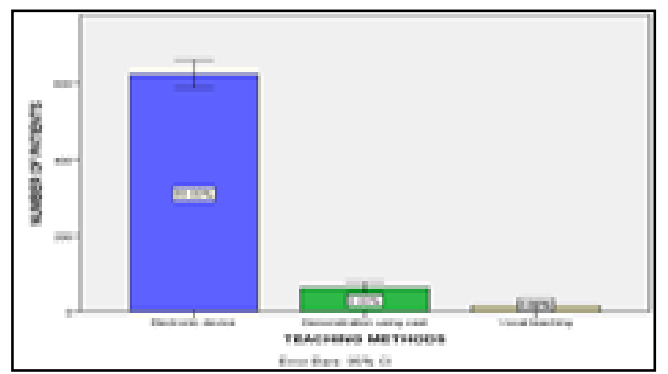

Figure 4. The graph represents the association between the mode of teaching and the gender of the patient. The $\mathrm{x}$ axis represents the gender of the patient and the $y$ axis represents the mode of teaching. The blue colour indicates teaching using electronic devices; green indicates demonstration using cast and yellow indicates vocal training. Electronic devices were commonly used to demonstrate for both male (45.2\%) and female (43.7\%) patients which was statistically significant. (Chi Square test; $\mathrm{p}$ value $=0.02 ; \mathrm{p}<0.05$ : hence significant $)$

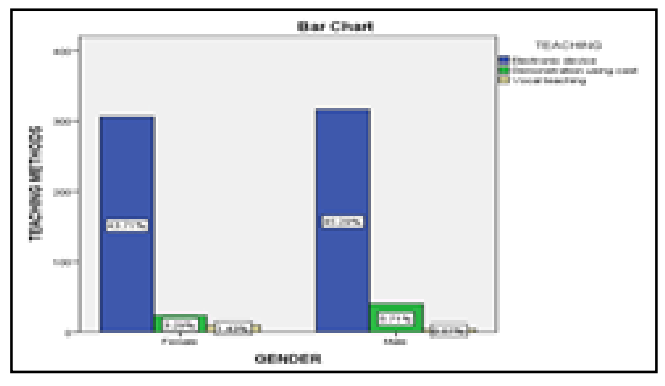

removal, sequelae of gingivitis and periodontitis and occurrence of dental caries has been clinically proven [36]. It is the responsibility of a dentist to incorporate such methods of brushing in patients, especially of the younger age group. The mode of teaching plays an important role in making sure the patient could process the right information and implement it in their everyday life.

In this study it was found that using electronic devices and reinforcement to implement the proper brushing techniques was found to be most preferred. This is more likely due to the fact that children nowadays tend to respond positively to audio-visual reinforcement compared to other methods. It is also less time consuming and easier for the dentist to convey information using such devices. This is in correlation with a study by Soraya et al., who found that children who were taught brushing techniques using audio-visual aids and individual reinforcement had better plaque control [37]. Vocal teaching was not as much preferred as patients of a younger age group may not remember the proper sequence of brushing and there may be a gap in understanding. However, a study by Williford et al.,[38] reported that educational lectures result in highly significant improvements in oral health when applied in adolescents. According to Simmons et al., [12], most children were not able to understand the use of prepositions such as "on top of", "inside", "behind", etc. Thus, the difficulty found in teaching tooth brushing skills to these children using just words. Therefore, other methods, such as audiovisual should be indicated for children with such difficulties [39]. Demonstration with a cast was preferred but it depends on the availability of casts. It can provide a good way of conveying the proper information to children.

The most crucial reason for proper, effective and frequent tooth brushing is to preserve the health of the oral cavity. It is also safe to say that, if proper tooth brushing habits are established at home, the clinical situation is more easily accepted by the child. Early establishment of good oral hygiene habits may also play a role in the perception of oral health of a child.

Advantage of this study was that it had easy access, the large availability of data and similar ethnicity. It was also used to identify any mistakes in the brushing techniques advised. Limitation of this study was that it had no external validity. The sample size was 
small and inadequate. It was a uni centered study with a geographic limitation. The future scope was that it should be conducted as a multi centered study with extension in the geographic limitation and to create more effective ways of teaching brushing technique to decrease the caries incidence and periodontal problems in children with permanent dentition.

\section{Conclusion}

Within the limits of this study, it can be concluded that using audiovisual aids like electronic devices are majorly preferred among dentists compared to vocal teaching or demonstration using cast to teach the proper brushing techniques to children of 13 to 18 years of age (permanent dentition stage). This data is useful because this method is both inexpensive and easily taught. It is imperative to find which method of oral hygiene instruction is more adequate for each child considering their age group as each child responds differently to different modes of teaching.

\section{Acknowledgement}

The authors are thankful to the Department of Pedodontics, Saveetha Dental College and Hospitals, Saveetha Institute of Medical and Technical sciences and Saveetha University for providing a platform to express my knowledge.

\section{Funding}

The present project is funded by:

- Saveetha Institute of Medical and Technical Sciences

- Saveetha Dental College and Hospitals

- Saveetha University

- Little Holy Angels Matriculation Higher Secondary school.

\section{References}

[1]. Institute of Medicine (US). Committee on the Future of Dental Education. Dental education at the crossroads: challenges and change. National Academies; 1995 Jan 26:368.

[2]. Chou R, Cantor A, Zakher B, Mitchell JP, Pappas M. Prevention of Dental Caries in Children Younger Than 5 Years Old: Systematic Review to Update the U.S. Preventive Services Task Force Recommendation [Internet]. Rockville (MD): Agency for Healthcare Research and Quality (US); 2014 May. Pubmed PMID: 24872964

[3]. Elamin A, Garemo M, Mulder A. Determinants of dental caries in children in the Middle East and North Africa region: a systematic review based on literature published from 2000 to 2019. BMC Oral Health. 2021 May 4;21(1):237.Pubmed PMID: 33947387.

[4]. Glick M, Williams DM, Kleinman DV, Vujicic M, Watt RG, Weyant RJ. A new definition for oral health developed by the FDI World Dental Federation opens the door to a universal definition of oral health. J Public Health Dent. 2017 Dec;77(1):3-5.

[5]. Al Subait AA, Alousaimi M, Geeverghese A, Ali A, El Metwally A. Oral health knowledge, attitude and behavior among students of age 10-18 years old attending Jenadriyah festival Riyadh; a cross-sectional study. Saudi J Dent Res. 2016 Jan 1;7(1):45-50.

[6]. Van Der Weijden F, Slot DE. Oral hygiene in the prevention of periodontal diseases: the evidence. Periodontology 2000. 2011 Feb;55(1):104-23.

[7]. Wilkins EM. Clinical Practice of the Dental Hygienist. 2010:1216 .

[8]. R B, Bharathi R, Ravindran V, Senthil MP. Assessment of brushing techniques taught by dental students to children in mixed dentition stage - A retrospective study. Int. j. res. pharm. sci. 2020;11: 977-82.

[9]. Arai T. A comparison of different toothbrushes and toothbrushing methods on plaque removal (author's transl). Nihon Shishubyo Gakkai Kaishi. 1976 Mar;18(1):13-31.Pubmed PMID: 1075059.

[10]. Sen Savara B, Suher T. Dental caries in children one to six years of age as related to socioeconomic level, food habits, and toothbrushing. J Dent Res. 1955 Dec;34(6):870-5.

[11]. Casanova-Rosado AJ, Medina-Solís CE, Casanova-Rosado JF, VallejosSánchez AA, Minaya-Sánchez M, Mendoza-Rodríguez M, et al. Tooth brushing frequency in Mexican schoolchildren and associated socio-demographic, socioeconomic, and dental variables. Med Sci Monit. 2014 Jun 7;20:938-44. Pubmed PMID: 24907713.

[12]. Simmons S, Smith R, Gelbier S. Effect of oral hygiene instruction on brushing skills in preschoolchildren. Community Dent Oral Epidemiol. 1983 Aug;11(4):193-8.

[13]. Anđelić I, Matijević S, Anđelić J. The importance of oral health behavior of children for their oral health. Sanamed. 2015;10(2):101-7.

[14]. Subramanyam D, Gurunathan D, Gaayathri R, Vishnu Priya V. Comparative evaluation of salivary malondialdehyde levels as a marker of lipid peroxidation in early childhood caries. Eur J Dent. 2018 Jan-Mar;12(1):67-70. Pubmed PMID: 29657527.

[15]. Ramadurai N, Gurunathan D, Samuel AV, Subramanian E, Rodrigues SJ. Effectiveness of $2 \%$ Articaine as an anesthetic agent in children: randomized controlled trial. Clin Oral Investig. 2019 Sep;23(9):3543-50.

[16]. Ramakrishnan M, Dhanalakshmi R, Subramanian EMG. Survival rate of different fixed posterior space maintainers used in Paediatric Dentistry - A systematic review. Saudi Dent J. 2019 Apr;31(2):165-172.Pubmed PMID: 30983825.

[17]. Jeevanandan G, Thomas E. Volumetric analysis of hand, reciprocating and rotary instrumentation techniques in primary molars using spiral computed tomography: An in vitro comparative study. Eur J Dent. 2018 JanMar;12(1):21-26.Pubmed PMID: 29657521.

[18]. Princeton B, Santhakumar P, Prathap L. Awareness on Preventive Measures taken by Health Care Professionals Attending COVID-19 Patients among Dental Students. Eur J Dent. 2020 Dec;14(S 01):S105-S109.Pubmed PMID: 33321549.

[19]. Saravanakumar K, Park S, Mariadoss AVA, Sathiyaseelan A, Veeraraghavan VP, Kim S, et al. Chemical composition, antioxidant, and anti-diabetic activities of ethyl acetate fraction of Stachys riederi var. japonica (Miq.) in streptozotocin-induced type 2 diabetic mice. Food Chem Toxicol. 2021 Sep; 155:112374.Pubmed PMID: 34186120.

[20]. Wei W, Li R, Liu Q, Seshadri VD, Veeraraghavan VP, Mohan SK, et al. Amelioration of oxidative stress, inflammation and tumor promotion by Tin oxide-Sodium alginate-Polyethylene glycol-Allyl isothiocyanate nanocomposites on the 1,2-Dimethylhydrazine induced colon carcinogenesis in rats. Arab. J. Chem. 2021 Jun 3;14(8):103238.

[21]. Gothandam K, Ganesan VS, Ayyasamy T, Ramalingam S. Antioxidant potential of theaflavin ameliorates the activities of key enzymes of glucose metabolism in high fat diet and streptozotocin - induced diabetic rats. Redox Rep. 2019 Dec;24(1):41-50.Pubmed PMID: 31142215.

[22]. Su P, Veeraraghavan VP, Krishna Mohan S, Lu W. A ginger derivative, zingerone-a phenolic compound-induces ROS-mediated apoptosis in colon cancer cells (HCT-116). J Biochem Mol Toxicol. 2019 Dec;33(12):e22403. Pubmed PMID: 31714660.

[23]. Mathew MG, Samuel SR, Soni AJ, Roopa KB. Evaluation of adhesion of Streptococcus mutans, plaque accumulation on zirconia and stainless steel crowns, and surrounding gingival inflammation in primary molars: randomized controlled trial. Clin Oral Investig. 2020 Sep;24(9):3275-3280.Pubmed PMID: 31955271.

[24]. Sekar D, Johnson J, Biruntha M, Lakhmanan G, Gurunathan D, Ross K. Biological and clinical relevance of microRNAs in mitochondrial diseases/ dysfunctions. DNA Cell Biol. 2020 Aug 1;39(8):1379-84.

[25]. Velusamy R, Sakthinathan G, Vignesh R, Kumarasamy A, Sathishkumar D, Priya KN, et al. Tribological and thermal characterization of electron beam physical vapor deposited single layer thin film for TBC application. Surf Topogr: Metrol Prop. 2021 Jun 24;9(2):025043.

[26]. Aldhuwayhi S, Mallineni SK, Sakhamuri S, Thakare AA, Mallineni S, Sajja R, et al. Covid-19 Knowledge and Perceptions Among Dental Specialists: A Cross-Sectional Online Questionnaire Survey. Risk Manag Healthc Policy. 2021 Jul 7;14:2851-2861.Pubmed PMID: 34262372.

[27]. Sekar D, Nallaswamy D, Lakshmanan G. Decoding the functional role of long noncoding RNAs (lncRNAs) in hypertension progression. Hypertens Res. 2020 Jul;43(7):724-725.Pubmed PMID: 32235913.

[28]. Bai L, Li J, Panagal M, M B, Sekar D. Methylation dependent microRNA $1285-5$ p and sterol carrier proteins 2 in type 2 diabetes mellitus. Artif Cells Nanomed Biotechnol. 2019 Dec;47(1):3417-3422.Pubmed PMID: 31407919.

[29]. Sekar D. Circular RNA: a new biomarker for different types of hypertension. Hypertens Res. 2019 Nov;42(11):1824-5.

[30]. Sekar D, Mani P, Biruntha M, Sivagurunathan P, Karthigeyan M. Dissecting the functional role of microRNA 21 in osteosarcoma. Cancer Gene Ther. 2019 Jul;26(7-8):179-182.Pubmed PMID: 30905966. 
[31]. Duraisamy R, Krishnan CS, Ramasubramanian H, Sampathkumar J, Mariappan S, Navarasampatti Sivaprakasam A. Compatibility of Nonoriginal Abutments With Implants: Evaluation of Microgap at the Implant-Abutment Interface, With Original and Nonoriginal Abutments. Implant Dent. 2019 Jun;28(3):289-295.Pubmed PMID: 31124826.

[32]. Parimelazhagan R, Umapathy D, Sivakamasundari IR, Sethupathy S, Ali D, Kunka Mohanram R, et al. Association between Tumor Prognosis Marker Visfatin and Proinflammatory Cytokines in Hypertensive Patients. Biomed Res Int. 2021 Mar 16;2021:8568926.Pubmed PMID: 33816632.

[33]. Syed MH, Gnanakkan A, Pitchiah S. Exploration of acute toxicity, analgesic, anti-inflammatory, and anti-pyretic activities of the black tunicate, Phallusia nigra (Savigny, 1816) using mice model. Environ Sci Pollut Res Int. 2021 Feb;28(5):5809-5821.Pubmed PMID: 32978735.

[34]. NAKAJIMA Y. Influences of brushing force and the number of brushing strokes on brushing effect during manual toothbrushing in adults. J Dent
Health. 1971;21(3):193-215.

[35]. Kaur K. Brushing Teeth. Brushing Teeth. 2019: 1-6.

[36]. Ganavadiya R, Shekar BRC, Goel P, Hongal SG, Jain M, Gupta R. Comparison of anti-plaque efficacy between a low and high cost dentifrice: A short term randomized double-blind trial. Eur J Dent. 2014 Jul;8(3):381388.Pubmed PMID: 25202220.

[37]. Leal SC, Bezerra AC, Toledo OA. Effectiveness of teaching methods for toothbrushing in preschool children. Braz Dent J. 2002;13:133-6.

[38]. Williford JW, Muhler JC, Stookey GK. Study demonstrating improved oral health through education. J Am Dent Assoc. 1967 Oct 1;75(4):896-902.

[39]. Karabekiroğlu S, Ünlü N. The Importance and Role of Early Prevention Practices in Community-Based Preventive Oral Health Programs. Journal of Ege University School of Dentistry. 2017;38: 89-100. 